\title{
Estimasi Parameter Capital Assets Pricing Model Dengan Metode Generalized Method of Moments Dalam Perhitungan Value At Risk
}

\author{
Diah Maghfiroh Wahyuni' ${ }^{1}$, Abdul Aziz² ${ }^{2}$ Juhari $^{2}$ \\ ${ }^{1}$ Mahasiswa Jurusan Matematika, Universitas Islam Negeri Maulana Malik Ibrahim Malang \\ 2Dosen Jurusan Matematika, Universitas Islam Negeri Maulana Malik Ibrahim Malang \\ Email : diah.almaghfiroh@gmail.com
}

\begin{abstract}
ABSTRAK
Capital Assets Pricing Model merupakan persamaan regresi antara premi risiko aset terhadap premi risiko pasar. Risiko ada jika pembuat keputusan tidak memiliki data untuk menyusun suatu dugaan. Pendugaan tersebut dapat dilakukan dengan generalized method of moments. Penelitian ini bertujuan untuk mengetahui hasil estimasi parameter pada Capital Assets Pricing Model menggunakan Generalized Method of Moments pada data saham PT. Indofood Tbk., serta mendapatkan nilai Value at Risk pada data saham PT. Indofood Tbk. Hasil yang diperoleh yaitu : $\hat{\beta}_{m}=\left(X^{\prime} Z \widehat{W}_{m} Z^{\prime} X\right)^{-1} X^{\prime} Z \widehat{W}_{m} Z^{\prime} Y, m=1,2, \ldots$. Dengan nilai $\beta=0,977217$ maka model regresi pada saham PT. Indofood Tbk.. yaitu $R_{t}-$ $F_{t}=0,977217\left(M_{t}-F_{t}\right)+\varepsilon_{t}$. Dengan tingkat signifikansi $5 \%$, investasi awal Rp10.000.000,00 , kerugian yang akan ditanggung oleh investor adalah Rp1.265.800,00 .
\end{abstract}

Kata Kunci : Capital Assets Pricing Model, Generalized Method of Moments, Value at Risk

\begin{abstract}
Capital Assets Pricing Model is a regression equation between risk premium assets against market risk premium. The risk will happen if the decision makers do not have data to compile an estimate. The estimation can be held by using generalized method of moments. This study aims to determine the parameter estimation results on Capital Assets Pricing Model by using the Generalized Method of Moments in PT. Indofood Tbk.. data, As well as getting Value at Risk in PT. Indofood Tbk. data. The results obtained are: $\hat{\beta}_{m}=$ $\left(X^{\prime} Z \widehat{W}_{m} Z^{\prime} X\right)^{-1} X^{\prime} Z \widehat{W}_{m} Z^{\prime} Y, m=1,2, \ldots$. With $\beta=0,977217$ then the regression model in PT. Indofood Tbk.. $R_{t}-F_{t}=0,977217\left(M_{t}-F_{t}\right)+\varepsilon_{t}$. With $5 \%$ of a significance level, the initial investment Rp10.000.000, -, the losses will be borne by the investor is Rp1.265.800, $-$
\end{abstract}

Keywords : Capital Assets Pricing Model, Generalized Method of Moments, Value at Risk

\section{PENDAHULUAN}

Capital Assets Pricing Model (CAPM) merupakan teori keuangan modern yang dapat mengukur hubungan risiko yang akan diperoleh berdasarkan keuntungan yang diharapkan [1]. Model CAPM adalah persamaan regresi antara premi risiko tingkat keuntungan (return) aset terhadap premi risiko tingkat keuntungan pasar investasi. Parameter $\beta$ dalam regresi CAPM adalah koefisien dari premi risiko return pasar. Dalam mencari Parameter $\beta$, dilakukan dengan menggunakan metode Generalized Method of Moments yaitu salah satu metode 
yang dapat mengatasi kondisi data dengan keberadaan autokorelasi atau heteroskedastisitas. Metode ini pertama kali diperkenalkan oleh Hansen pada tahun 1982 yang didefinisikan sebagai metode estimasi parameter yang meminimalkan bentuk kuadrat dari kondisi momen sampel yang terboboti matriks $W_{T}$. Selanjutnya, bahwa akhir-akhir ini risiko investasi juga bukan lagi diukur berdasarkan deviasi standar, melainkan diukur dengan menggunakan kuantil atau lebih dikenal dengan Value at Risk (VaR). Secara sederhana VaR ingin menjawab pertanyaan "seberapa besar (dalam persen atau sejumlah uang tertentu) investor dapat merugi selama waktu investasi $T$ dengan tingkat kepercayaan sebesar $\alpha$ ?". Dari pernyataan tersebut secara sederhana melihat adanya tiga variabel yang penting: besar kerugian, selang waktu, dan besar tingkat kepercayaan.

Estimasi (estimation) adalah proses yang menggunakan sampel statistik untuk menduga atau memperkirakan hubungan parameter populasi yang tidak diketahui berdasarkan informasi dari sampel. Dalam hal ini, peubah acak akan diambil dari populasi yang bersangkutan. Jadi, dengan estimasi ini, keadaan parameter populasi dapat diketahui [2]. Estimasi dapat diartikan sebagai penentuan nilai-nilai yang diperoleh dari data sampel dan dapat digunakan sebagai pengganti nilai parameter yang tidak diketahui [3]. Return merupakan hasil yang didapatkan dari investasi. Return dapat berupa actual return yang sudah terjadi atau berupa expected return yang belum terjadi tetapi yang diharapkan terjadi di masa mendatang. Return dihitung dengan rumus:

$$
R_{t}=\frac{P_{t}-P_{t-1}}{P_{t-1}}
$$

dimana R adalah return saham pada waktu $t, P_{t}$ adalah harga saham sekarang, dan $P_{t-1}$ adalah harga saham sebelumnya [4].

Definisi CAPM menurut Jack Clark Francis adalah teori penilaian risiko dan keuntungan aset yang didasarkan koefisien beta (indeks risiko yang tidak dapat didiversivikasi) [5]. Menurut [6] CAPM disusun sebagai gambaran bahwa premi risiko yang tepat terhadap suatu aset akan ditentukan oleh kontribusinya terhadap risiko dari seluruh portofolio investor. Satu prinsip dasar dari keseimbangan adalah bahwa seluruh investasi seharusnya menawarkan rasio imbal hasil terhadap risiko yang sama. Jika rasio ini lebih baik pada satu investasi dibandingkan investasi lain, maka investor akan mengatur ulang portofolionya.

Pada standar CAPM diasumsikan nilai $\beta_{0}$ bernilai nol. Persamaannya sebagai berikut :

$$
R_{t}-F_{t}=\beta\left(M_{t}-F_{t}\right)+\varepsilon_{t}
$$

Generalized Method of Moment (GMM) merupakan metode penaksiran parameter perluasan dari metode momen. Metode momen tidak dapat digunakan apabila banyaknya variabel instrumen lebih besar dibandingkan dengan jumlah parameter yang akan ditaksir. GMM menyamakan momen kondisi dari populasi dengan momen kondisi dari sampel. Metode GMM merupakan salah satu metode yang dapat mengatasi kondisi data dengan pelanggaran asumsi-asumsi pada analisis regresi. GMM didapat dengan cara meminimumkan jumlah kuadrat terboboti dari momen kondisi sampel [3].

Estimasi GMM untuk $\beta$ merupakan suatu estimasi $(\hat{\beta})$ yang meminimumkan fungsi jumlah kuadrat eror dari data regresi yang berbobot $Q(\hat{\beta})$ sebagai berikut [7]:

$$
Q(\hat{\beta})=\bar{g}(\hat{\beta})^{\prime} \widehat{W} \bar{g}(\hat{\beta})
$$


VaR merupakan sebuah konsep yang digunakan dalam pegukuran risiko dalam risk management. Secara sederhana VaR ingin menjawab pertanyaan "seberapa besar (dalam persen atau sejumlah uang tertentu) investor dapat merugi selama waktu investasi $T$ dengan tingkat kepercayaan sebesar $\alpha$ ?". Dari pernyataan tersebut secara sederhana melihat adanya tiga variabel yang penting: besar kerugian, selang waktu, dan besar tingkat kepercayaan sebesar [8].

Estimasi $V a R$ adalah [9]:

$$
\operatorname{VaR}(\alpha)=W_{o} \times\left\{\mu+\Phi^{-1}(\alpha) \sigma\right\}
$$

dengan $W_{0}$ adalah dana investasi awal saham oleh investor.

\section{METODE}

Pendekatan yang digunakan dalam penelitian ini adalah pendekatan literatur dan kuantitatif. Pendekatan literatur digunakan dalam menganalisis model CAPM dan untuk mrnrntukan estimasi parameter dari model CAPM menggunakan metode Generalized Method of Moment (GMM). Studi kasus digunakan untuk mengaji kerugian yang diperoleh investor setelah menginvestasikan dananya. berikut:

Langkah-langkah yang dilakukan dalam penelitian ini adalah sebagai

1. Menentukan bentuk estimator parameter model CAPM dengan metode GMM sebagai berikut :

a. Menyederhanakan model CAPM ke dalam bentuk regresi linier

b. Mengasumsikan persamaan regresi mengandung variabel instrumen $z_{t}$ dimana $z_{t}$ adalah sebagian atau keseluruhan dari variabel $x_{t}$ yang tidak berkorelasi dengan $\varepsilon_{t}$.

c. Menemukan momen kondisi sampel dari rata-rata galat sampel

d. Mensubstitusikan persamaan momen kondisi sampel pada persamaan GMM, kemudian menurunkannya terhadap $\hat{\beta}$ sehingga diperoleh $\hat{\beta}_{G M M}$

e. Mencari nilai pembobot $(\widehat{W})$ untuk menentukan nilai $\hat{\beta}$ sampai beberapa iterasi hingga ditemukan nilai $\hat{\beta}$ yang konvergen

2. Melakukan implementasi data pada data saham penutupan PT. Indofood Tbk. sebagai berikut :

a. Menentukan data return aset $r_{t}$, data return pasar $r_{m t}$, dan data aset bebas risiko $r_{f}$ dengan menggunakan rumus

$$
R_{t}=\frac{P_{t}-P_{t-1}}{P_{t-1}}
$$

b. Melakukan uji asumsi data yang meliputi deskriptif data, uji stasioneritas, uji normalitas, uji autokorelasi dengan Durbin-Watson, dan uji heteroskedastisitas dengan uji Breusch-Pagan.

c. Melakukan pendugaan parameter regresi model CAPM menggunakan program E-Views

3. Menghitung Nilai VaR PT Indofood Tbk.. (INDF)

a. Mencari nilai rata-rata dan standar deviasi return perusahaan setelah dikurangi aset bebas risiko.

b. Memasukkan nilai rata-rata dan standar devisi kedalam rumus VaR 
c. Menganalisis hasil perhitungan VaR

\section{HASIL DAN PEMBAHASAN}

\section{a. Estimasi Parameter pada Model CAPM dengan Metode GMM}

Pada standar CAPM diasumsikan nilai $\beta_{0}$ bernilai nol. Persamaannya sebagai berikut :

dimana

$$
R_{t}-F_{t}=\beta\left(M_{t}-F_{t}\right)+\varepsilon_{t}
$$

$R_{t} \quad$ : return saham perusahaan periode ke- $\mathrm{t}$

$M_{t} \quad$ : return portofolio pasar periode ke-t

$F_{t} \quad:$ suku bunga bebas risiko periode ke-t

$\beta \quad$ : tolak ukur risiko

$R_{t}-F_{t} \quad$ : premi risiko investasi perusahaan

$M_{t}-F_{t} \quad$ : premi risiko pasar

$\varepsilon_{t} \quad$ : galat periode ke-t

Persamaan (4.1) di atas dapat disederhanakan menjadi :

$$
y_{t}=x_{t} \beta+\varepsilon_{t}, \quad t=1,2, \ldots, T
$$

dimana,

$$
y_{t}=R_{t}-F_{t} \text { dan } x_{t}=M_{t}-F_{t}
$$

Persamaan (4.2) diasumsikan mengandung variabel instrumen $z_{t}$ dimana $z_{t}$ adalah sebagian atau keseluruhan dari variabel eksplanatori $\left(x_{t}\right)$ yang tidak berkorelasi dengan $\varepsilon_{t}$ sebagai berikut :

Sehingga rata-rata galat sampel menjadi :

$$
z_{t} y_{t}=z_{t} x_{t} \beta+z_{t} \varepsilon_{t}, \quad t=1,2, \ldots, T
$$

dimana

$$
\bar{g}(\hat{\beta})=\frac{1}{T} \sum_{t=1}^{T}\left(z_{t} y_{t}-z_{t} x_{t} \hat{\beta}\right)=\frac{1}{T}\left(Z^{\prime} Y-Z^{\prime} X \hat{\beta}\right)
$$

$\hat{\beta}=$ estimator parameter $\beta ; Z=\left[\begin{array}{c}z_{1} \\ z_{2} \\ \vdots \\ z_{T}\end{array}\right]$; vektor berukuran $T \times 1$

$Y=\left[\begin{array}{c}y_{1} \\ y_{2} \\ \vdots \\ y_{T}\end{array}\right]$; vektor berukuran $T \times 1 ; X=\left[\begin{array}{c}x_{1} \\ x_{2} \\ \vdots \\ x_{T}\end{array}\right]$; vektor berukuran $T \times 1$

Metode GMM didefinisikan sebagai suatu estimasi parameter yang meminimumkan bentuk kuadrat dari kondisi momen sampel data regresi yang terboboti, yang secara simbolis dituliskan sebagai berikut:

$$
Q(\hat{\beta})=\bar{g}(\hat{\beta})^{\prime} \widehat{W} \bar{g}(\hat{\beta})
$$

dengan $\bar{g}(\hat{\beta})=\frac{1}{T}\left(Z^{\prime} Y-Z^{\prime} X \hat{\beta}\right)$ maka diperoleh solusi parameter $\hat{\beta}$ GMM pada model CAPM yaitu :

$$
\hat{\beta}=\left(X^{\prime} Z \widehat{W} Z^{\prime} X\right)^{-1} X^{\prime} Z \widehat{W} Z^{\prime} Y
$$

dengan $m$ iterasi, akan diperoleh nilai $\hat{\beta}$ yang konvergen sebagai berikut : 


$$
\hat{\beta}_{m}=\left(X^{\prime} Z \widehat{W}_{m} Z^{\prime} X\right)^{-1} X^{\prime} Z \widehat{W}_{m} Z^{\prime} Y, \quad m=1,2, \ldots
$$

\section{b. Implementasi Data}

\section{Analisis Deskriptif Data}

Tabel 4.1 Statistik Deskriptif Data Saham

\begin{tabular}{lccccc}
\multicolumn{5}{c}{ Descriptive Statistics } \\
& N & $\begin{array}{c}\text { Minimu } \\
\text { m }\end{array}$ & $\begin{array}{c}\text { Maximu } \\
\text { m }\end{array}$ & Mean & $\begin{array}{c}\text { Std. } \\
\text { Deviation }\end{array}$ \\
\hline Close IHSG & 184 & 4121 & 4915 & 4592,51 & 189,327 \\
Close INDF & 184 & 4680 & 7475 & 6003,29 & 804,622 \\
Valid N & 184 & & & & \\
(listwise) & & & & & \\
\hline
\end{tabular}

Sumber : Output SPSS 21

\section{Uji Stasioneritas}

Stasioneritas data dapat dilihat pada gambar di bawah ini
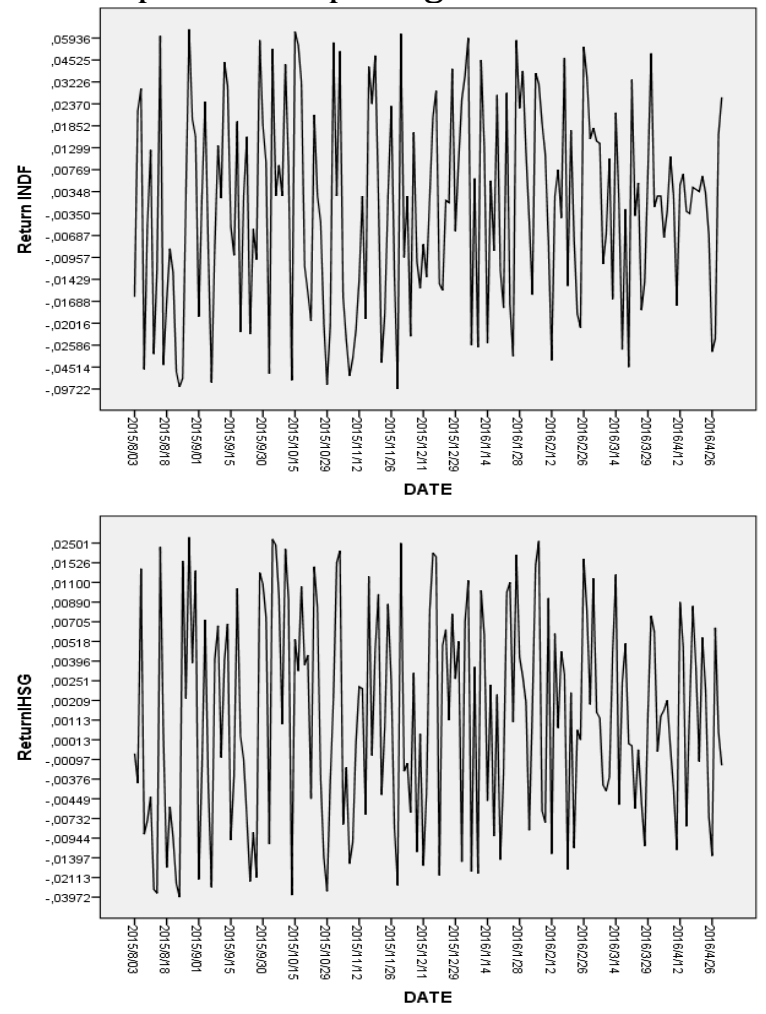

Gambar 4.2 Plot Data Return Saham PT. Indofood Tbk. (INDF) dan IHSG

\section{Uji Normalitas}

Hasil uji normalitas terdapat pada Tabel sebagai berikut :

Tabel 4.2 Uji Kolmogorof-Smirnov Data Return Saham INDF dan IHSG

One-Sample Kolmogorov-Smirnov Test 


\begin{tabular}{|c|c|c|c|}
\hline & & $\begin{array}{c}\text { ReturnIHS } \\
\text { G }\end{array}$ & $\begin{array}{l}\text { Return } \\
\text { INDF }\end{array}$ \\
\hline \multirow[t]{2}{*}{$\mathrm{N}$} & & 184 & 184 \\
\hline & Mean & 0001107 & 0012549 \\
\hline Normal Parameters ${ }^{a, b}$ & $\begin{array}{l}\text { Std. } \\
\text { Deviation }\end{array}$ & 01186025 & 02872924 \\
\hline \multirow{3}{*}{$\begin{array}{l}\text { Most Extreme } \\
\text { Differences }\end{array}$} & Absolute & ,085 & 094 \\
\hline & Positive &, 060 & 094 \\
\hline & Negative &,- 085 &,- 065 \\
\hline \multicolumn{2}{|c|}{ Kolmogorov-Smirnov Z } & 1,147 & 1,268 \\
\hline \multicolumn{2}{|l|}{ Asymp. Sig. (2-tailed) } &, 144 &, 080 \\
\hline
\end{tabular}

Sumber : Output SPSS 21

\section{Uji Autokorelasi}

Hasil uji autokorelasi terdapat pada Tabel sebagai berikut :

Tabel 4.3 Nilai Durbin-Watson Saham INDF

\begin{tabular}{|c|c|c|c|c|c|}
\hline \multicolumn{6}{|c|}{ Model Summaryb } \\
\hline Model & $\mathrm{R}$ & R Square & $\begin{array}{l}\text { Adjusted R } \\
\text { Square }\end{array}$ & $\begin{array}{l}\text { Std. Error of } \\
\text { the Estimate }\end{array}$ & $\begin{array}{l}\text { Durbin- } \\
\text { Watson }\end{array}$ \\
\hline 1 &, $678^{a}$ & ,460 & ,457 & ,02117499 & 1,653 \\
\hline
\end{tabular}

Sumber : Output SPSS 21

\section{Uji Heteroskedastisitas}

Hasil uji heteroskedastisitas terdapat pada Tabel sebagai berikut :

Tabel 4.4 Hasil Uji Breusch-Pagan and Koenker Saham INDF

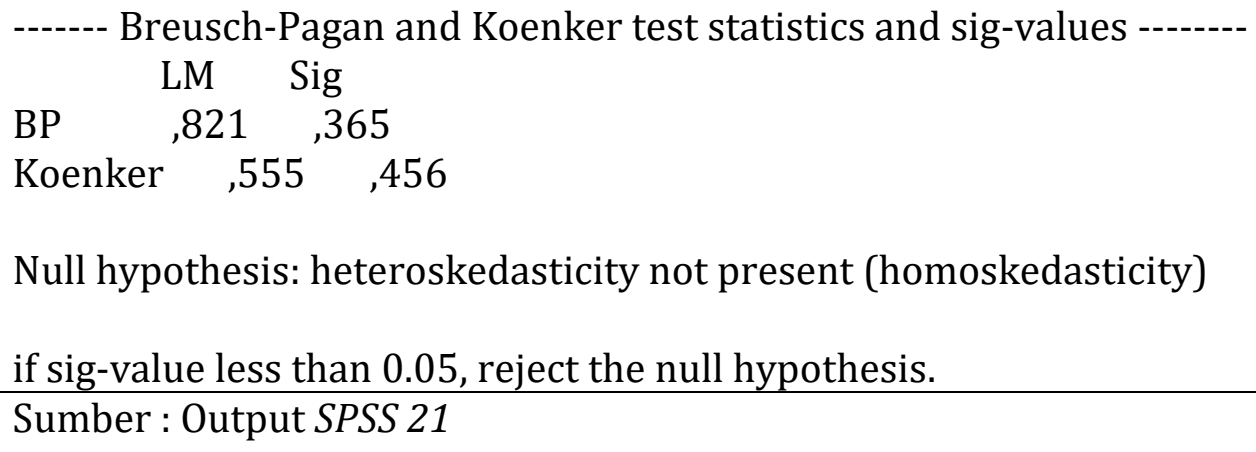

\section{c. Hasil Estimasi Parameter}

Hasil dari estimasi tersebut tertera pada Tabel 4.5 di bawah ini:

Tabel 4.5 Hasil Estimasi Parameter Model CAPM saham INDF 


\begin{tabular}{|c|c|c|c|}
\hline $\begin{array}{l}\text { Dependent Variab } \\
\text { Method: Generaliz } \\
\text { Date: } 02 / 09 / 17 \\
\text { Sample (adjusted) } \\
\text { Included observat } \\
\text { Linear estimation } \\
\text { Estimation weigh } \\
\text { West fixed } \\
\text { bandwidth = } \\
\text { Standard errors \& } \\
\text { weighting matrix } \\
\text { Convergence achi } \\
\text { Instrument specif } \\
\text { Constant added to }\end{array}$ & $\begin{array}{l}\text { RY } \\
\text { d Method of } \\
\text { me: } 09: 59 \\
\text { 8/04/2015 } \\
\text { ons: } 183 \text { afte } \\
\text { iterate wei } \\
\text { ng matrix: H } \\
\text { 0000) } \\
\text { ovariance cc } \\
\text { jed after } 6 \text { w } \\
\text { ation: RX } \\
\text { nstrument li }\end{array}$ & $\begin{array}{l}\text { Moments } \\
\text { 2/02/2016 } \\
\text { r adjustments } \\
\text { hts } \\
\text { AC (Bartlett kernel, Ne } \\
\text { mputed using estimati } \\
\text { eight iterations }\end{array}$ & $\begin{array}{l}\text { wey- } \\
\text { ion }\end{array}$ \\
\hline Variable & Coefficient & Std. Error t-Statistic & Prob. \\
\hline $\mathrm{RX}$ & 0.977217 & 0.022236 & 0.0000 \\
\hline $\begin{array}{l}\text { R-squared } \\
\text { Adjusted R- } \\
\text { squared } \\
\text { S.E. of regression } \\
\text { Durbin-Watson } \\
\text { stat } \\
\text { Instrument rank }\end{array}$ & $\begin{array}{l}0.401210 \\
0.021990\end{array}$ & $\begin{array}{l}\text { S.D. dependent var } \\
\text { Sum squared resid } \\
\text { J-statistic } \\
\text { Prob(J-statistic) }\end{array}$ & $\begin{array}{l}0.071751 \\
0.028418 \\
0.088009\end{array}$ \\
\hline
\end{tabular}

Sumber : output Eviews 7

\section{d.Menghitung Nilai VaR Saham PT. Indofood (INDF)}

Perhitungan $V a R$ dapat dilakukan dengan persamaan (2.31), nilai Z-Tabel dengan $\alpha=0,05$ adalah sebesar 1,960, dan dimisalkan investasi awal $\left(W_{o}\right)$ investor sebesar Rp10.000.000,00. Prosesnya sebagai berikut :

$$
\begin{aligned}
\operatorname{VaR}(\alpha) & =W_{o} \times\left\{\mu+\Phi^{-1}(\alpha) \sigma\right\} \\
& =10.000 .000 \times\{0,0717+1,960 \times 0,028\} \\
& =10.000 .000 \times\{0,0717+0,05488\} \\
& =10.000 .000 \times\{0,12658\}=1265800
\end{aligned}
$$

Jadi, dengan tingkat signifikansi $5 \%$, maksimum kerugian yang terjadi dan harus ditanggung oleh investor adalah sebesar Rp1.265.800,00 .

\section{KESIMPULAN}

Berdasarkan hasil pembahasan dalam skripsi ini, maka dapat diambil kesimpulan sebagai berikut : Hasil estimasi parameter pada model CAPM menggunakan metode GMM secara iteratif yaitu $\hat{\beta}_{m}=$ $\left(X^{\prime} Z \widehat{W}_{m} Z^{\prime} X\right)^{-1} X^{\prime} Z \widehat{W}_{m} Z^{\prime} Y, m=1,2,3, \ldots$. Hasil estimasi parameter model CAPM dengan metode GMM pada data saham penutupan PT. Indofood Tbk. yaitu $\beta=$ 
0,977217. Sehingga model regresi pada saham INDF sebagai berikut : $R_{t}-F_{t}=$ $0,977217\left(M_{t}-F_{t}\right)+\varepsilon_{t}$. Dengan tingkat signifikansi $5 \%$, dan dengan investasi awal sebesar Rp10.000.000,00, maksimum kerugian yang terjadi dan harus ditanggung oleh investor adalah sebesar Rp1.265.800,00 .

\section{DAFTAR RUJUKAN}

[1] M. A. Shamim, "Validity of CAPM in Pakistan's Capital Market (Karachi Stok Exchage)," Journal of Emerging Issues in Economic, Finance, and Banking, pp. 1141-1149, 2014.

[2] M. I. Hasan, Pokok-Pokok Materi Statistik, Jakarta: PT. Bumi Aksara, 2002.

[3] M. Taurif, "Estimation of Generalized Mehod of Moments in Logistic Regression Model," Prosiding Seminar Nasional Matematika Unej 2014, pp. 167-174, 2014.

[4] W. Sharpe, Investasi, Jakarta: Indeks Gramedia, 2005.

[5] A. Kamarudin, Dasar-dasar Investasi, Jakarta: PT. Rineka Cipta, 2004.

[6] Bodie, Kane and Marcus, Investments, Jakarta: Salemba Empat, 2005.

[7] D. Astutik, Estimasi Parameter Model Data Panel Dinamis dengan Metode Momen Ahn dan Schmidt, Malang: UIN Maulana Malik Ibrahim Malang, 2013.

[8] D. Harper, "Introduction to Value at Risk," 2004. [Online]. Available: http://www.investopedia.com/. [Accessed 11 Februari 2017].

[9] A. McNeil, Quantitative Risk Management, New Jersey: Pricenton University Press, 1967.

[10] J. Hartono, Teori Portofolio dan Analisis Investasi, Yogyakarta: BPFE, 2008. 